\title{
Extended SMC for a stand-alone wound rotor
}

\section{synchronous generator}

\author{
Raúl-S. Muñoz-Aguilar \\ Universitat Politècnica de Catalunya \\ Department of Electrical Engineering \\ 08222 Terrassa, Spain \\ Email: raul.munoz-aguilar@upc.edu
}

\author{
Arnau Dòria-Cerezo \\ Universitat Politècnica de Catalunya \\ Department of Electrical Engineering, \\ 08028 Barcelona, Spain \\ Email: arnau.doria@upc.edu
}

\section{Enric Fossas}

Universitat Politècnica de Catalunya

Department of Automatic Control,

08028 Barcelona, Spain

Email: enric.fossas@upc.edu

\begin{abstract}
In this paper, a sliding mode controller for the stator voltage amplitude of a stand-alone wound rotor synchronous generator is presented. The standard dq-model of the electrical machine connected to an isolated inductive load is obtained. Then, the control law is designed using sliding mode techniques. The controller introduces a dynamic extension so that the stator voltage amplitude has relative degree one. As a result, a fast controller, robust to both machine and load parameters variations, is obtained. The control algorithm, that does not requires the knowledge of the parameters, is implemented and validated experimentally.
\end{abstract}

Index Terms 
Variable structure systems, Voltage control, Synchronous generators, Sliding mode control.

\section{INTRODUCTION}

Applications related with the production, transportation and consumption of electrical energy are widely studied. The increasing use of the electrical energy is due to the advantages of transmission possibilities, flexibility and control capacity among others. Electrical energy is mainly generated by interconnecting electric generators driven by prime-movers which are basically wind, hydro, steam turbines or internal combustion engines. Standard power generators are Wound Rotor Synchronous Generators (WRSG) connected in parallel setting up a theoretical infinite bus. Hence, this kind of machine is normally studied connected to an infinite bus called "power grid" [1]. The own grid determines the stator voltage and frequency, while the rotor voltage helps to improve the power factor and to compensate the reactive power at the connection point. Usually, the stator transients can be neglected [2].

A significantly different scenario is when the synchronous generator is isolated from the grid. This paper is focused on the stand-alone case of the wound rotor synchronous machine where neither amplitude nor frequency of stator voltage are fixed. For this isolated configuration, the mechanical speed determines the frequency, and the rotor voltage is used to set the stator voltage amplitude. This topology is used in many applications as isolated electrical power generation (for instance uninterruptible power supplies, UPS) with an internal combustion engine, aircraft electric systems [3], ship electrical power generation [4], wind turbines [5] or in propulsion systems for Hybrid Electric Vehicles [6] [7].

Several examples can be found in the literature about the control of synchronous machines. The permanent magnet case (PMSM, Permanent Magnet Synchronous Machine) is the most studied. Examples for controlling PMSM include linear techniques [8], Model Predictive Controls [9], direct torque control [10], hybrid sensorless control [11]and, recently, nonlinear control techniques such as Passivity-based control [12] Optimal torque control [13], Fault-Tolerant Control [14] or Lyapunov-based designs [15] are also used for driving applications. 
However, examples for the WRSG are not so extensive. The stator voltage regulation has been mainly studied using linear techniques. From classical approaches in [16] and [17] or a PID design [18], to a more sophisticated methods as pole assignment self tuning technique [19] or, more recently, using $H_{\infty}$ algorithms [20] or Robust controllers [21]. Linear control methodology is usually insufficient for inherent nonlinear high-order multivariable plants such as AC machines where parameter changes caused by winding temperature variation, converter switching effect and saturation are well recognized and infrequently accounted for. Sliding mode control technique, with its distinctive features (order reduction, disturbance rejection and strong robustness with a minimum of implementation complexity [22]), had arisen the interest of many researchers in power electronics [23] and electrical machines.

The sliding mode control methodology has already been used for a generator in a stand-alone configuration. The design obtained in [24], valid only for static loads, includes a virtual high value resistances into the model to compute the voltages in the stator side. In this case, the controller results in a complex function which depends on both the machine and load parameters and requires the measurement of the whole state. A different approach, taking into account the load model, is presented in [25] and [26]. The result are simple and robust control algorithms but only valids for the resistive case.

The main contribution of this work is an experimentally tested sliding mode control algorithm for a stand alone wound rotor synchronous generator with resistive-inductive load. In this case, SMC cannot be directly applied, because the desired system output (the stator voltage amplitude) is relative degree zero. Instead, a dynamical extension of the system is proposed so that the output relative degree is one. SMC makes closed loop system robust to machine and load parameter variations and, moreover, local stability of the closed loop dynamics can be proved by using nonlinear techniques. The resulting controller, which only uses the stator voltage measurements and neither the machine parameters nor load knowledge are required, is easy to implement (with a low CPU use) and shows a good performance and a fast response as well. 
The paper is organized as follows. Section II deals with the WRSM model, the control goals and the equilibrium points. The synthesis and analysis of a SMC are presented in Section III. Section IV is devoted to a brief description of the hardware used for experiments which, in turn, are reported in Section V. Finally, conclusions are drawn in Section VI.

\section{SYSTEM DESCRIPTION}

Figure 1 shows the proposed scenario: a primary mover drags, at a constant speed, a WRSM which acts as a generator to feed a resistive-inductive isolated load. Is worth to mention that, due to the constant speed assumption, electric wind turbines (which require working with a variable speed range [27]) does not follow the proposed scheme.

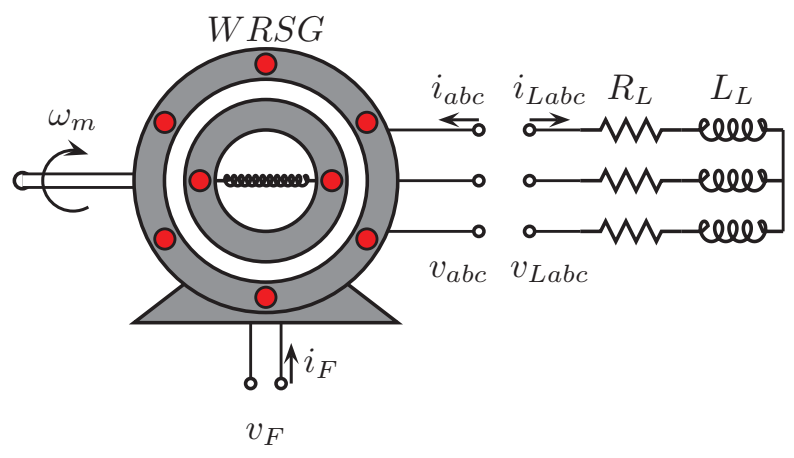

Figure 1. Scheme of a stand alone wound rotor synchronous generator.

As explained before, this system differs from the typical grid-connected systems in that, in the last case, the frequency and the voltage amplitude are fixed by the grid. For a stand-alone connection the frequency is determined by the mechanical speed, $\omega_{m}$, (provided by the primary mover), while the voltage amplitude is set by the rotor field voltage. This configuration can be found in several scenarios, an example is the Series Hybrid Electric Vehicles in which the rotor power excitation is obtained from a on board battery pack [6]. 


\section{A. Dynamic model}

From the dynamic equations, in dq-coordinates [28], of a cylindrical-rotor $\mathrm{WRSG}^{1}$ and the interconnection rules with an inductive load, the whole dynamical system is presented.

The electrical part of the wound rotor synchronous machine can be described as

$$
L \frac{\mathrm{d} x}{\mathrm{~d} t}=\left(\begin{array}{ccc}
-R_{s} & \omega L_{s} & 0 \\
-\omega L_{s} & -R_{S} & -\omega L_{m} \\
0 & 0 & -R_{F}
\end{array}\right) x+\left(\begin{array}{c}
v_{d} \\
v_{q} \\
v_{F}
\end{array}\right)
$$

where

$$
L=\left(\begin{array}{ccc}
L_{s} & 0 & L_{m} \\
0 & L_{s} & 0 \\
L_{m} & 0 & L_{F}
\end{array}\right)
$$

is the inductance matrix, $x^{T}=\left(i_{d}, i_{q}, i_{F}\right) \in \mathbb{R}^{3}$ are the dq-stator and field currents, $R_{s}$ and $R_{F}$ are the stator and field resistances, $L_{s}, L_{m}$ and $L_{F}$ are the stator, mutual and field inductances, $\omega$ is the electrical speed $\left(\omega=n_{p} \omega_{m}\right.$, where $n_{p}$ is the number of pole pairs), $v_{d}, v_{q}$ are the dq-stator voltages and $v_{F}$ is the field voltage which will be used as a control input.

As a first approximation, the load is modeled by a pure resistive element, $R_{L}$, in series with a pure inductive element, $L_{L}$. All the possible variations (and complexities) of the actual load with respect to the simple RL load can be seen as derivations from the ideal model and, consequently, should be compensated by the robustness of the used controller. This can be appreciated during the experimental validation, when a realistic case of an induction motor as a load is presented. The load equation is given by

$$
v_{L}=\left(R_{L} I_{2}+\omega L_{L} J_{2}\right) i_{L}+L_{L} \frac{\mathrm{d}}{\mathrm{d} t} i_{L}
$$

\footnotetext{
${ }^{1}$ Since the mechanical speed is provided by an external prime-mover, and the electrical and mechanical time constant have different magnitude orders, the mechanical speed is considered constant and externally regulated.
} 
where $v_{L}^{T}=\left(v_{L d}, v_{L q}\right) \in \mathbb{R}^{2}$ and $i_{L}^{T}=\left(i_{L d}, i_{L q}\right) \in \mathbb{R}^{2}$ are the dq voltages and currents, and

$$
I_{2}=\left(\begin{array}{cc}
1 & 0 \\
0 & 1
\end{array}\right) \quad J_{2}=\left(\begin{array}{cc}
0 & -1 \\
1 & 0
\end{array}\right) .
$$

According to Figure 1, the interconnection rules are

$$
\begin{aligned}
& v_{s}=v_{L} \\
& i_{L}=-i_{s} .
\end{aligned}
$$

Thus, putting together (1), (2) and (3), the system can be written in an affine form as

$$
\hat{L} \frac{\mathrm{d} x}{\mathrm{~d} t}=A x+B v_{F},
$$

where $\hat{L}$ is a new inductance matrix,

$$
\hat{L}=\left(\begin{array}{ccc}
L_{s}+L_{L} & 0 & L_{m} \\
0 & L_{s}+L_{L} & 0 \\
L_{m} & 0 & L_{F}
\end{array}\right)
$$

and the homogeneous dynamics $A$ and the input vector $B$ are respectively given by

$$
A=\left(\begin{array}{ccc}
-\left(R_{S}+R_{L}\right) & \omega\left(L_{s}+L_{L}\right) & 0 \\
-\omega\left(L_{S}+L_{L}\right) & -\left(R_{S}+R_{L}\right) & -\omega L_{m} \\
0 & 0 & -R_{F}
\end{array}\right)
$$

and

$$
B=\left(\begin{array}{c}
0 \\
0 \\
1
\end{array}\right) \text {. }
$$




\section{B. Control objective}

As mentioned before, this machine must ensure the stator voltage amplitude and frequency. For a synchronous machine, the stator frequency is directly given by the mechanical speed which, in this paper, is assumed to be constant and externally regulated. Then, the system output is the stator voltage amplitude $V_{s}=\sqrt{v_{d}^{2}+v_{q}^{2}}$, that using (2) and (3) results in

$$
\begin{aligned}
V_{s}^{2}= & \left(-R_{L} i_{d}+\omega L_{L} i_{q}-L_{L} \frac{\mathrm{d} i_{d}}{\mathrm{~d} t}\right)^{2} \\
& +\left(-R_{L} i_{q}-\omega L_{L} i_{d}-L_{L} \frac{\mathrm{d} i_{q}}{\mathrm{~d} t}\right)^{2}
\end{aligned}
$$

From (4)

$$
\begin{aligned}
\mu_{d} \frac{\mathrm{d} i_{d}}{\mathrm{~d} t}= & L_{F}\left(-\left(R_{s}+R_{L}\right) i_{d}+\omega\left(L_{s}+L_{L}\right) i_{q}\right) \\
& -L_{m}\left(-R_{F} i_{F}+v_{F}\right) \\
\mu_{q} \frac{\mathrm{d} i_{q}}{\mathrm{~d} t}= & -\omega\left(L_{s}+L_{L}\right) i_{d}-\left(R_{s}+R_{L}\right) i_{q}-\omega L_{m} i_{F}
\end{aligned}
$$

where $\mu_{d}=L_{F}\left(L_{s}+L_{L}\right)-L_{m}^{2}$ and $\mu_{q}=L_{s}+L_{L}$.

Notice that, while the system dynamics is linear, as equation (4) indicates, $V_{s}$, is a tedious highly nonlinear function, which can be obtained replacing (6) and (7) in (5). Additionally, even for a pure resistive load the stator voltage is relative degree one [25], when loads include inductive terms, the stator voltage is relative degree zero. It is appropriate to mention here that having relative degree one is a necessary condition for a switching surface to have sliding modes on it. Hence, the standard procedure used in the resistive case will be modified through a dynamic extension.

\section{Equilibrium points}

The equilibrium points can be parametrized by the control input $v_{F}$, this resulting in

$$
x^{*}=-A^{-1} B v_{F},
$$


which defines the straight line

$$
x^{* T}=\left[-\frac{\omega^{2}\left(L_{s}+L_{L}\right) L_{m}}{R_{F}\left|Z_{s}\right|^{2}},-\frac{\omega\left(R_{s}+R_{L}\right) L_{m}}{R_{F}\left|Z_{s}\right|^{2}}, \frac{1}{R_{F}}\right] v_{F}
$$

where $\left|Z_{S}\right|^{2}=\omega^{2}\left(L_{s}+L_{L}\right)^{2}+\left(R_{S}+R_{L}\right)^{2}$.

The desired equilibrium point is defined by $V_{s}=V_{r e f}$. From (5), (6) and (7), and taking into account that two solutions are possible, the field voltage $v_{F}$ in equilibrium is

$$
v_{F}^{*}= \pm \frac{\left|Z_{S}\right|}{\left|Z_{L}\right|} \frac{R_{F}}{\omega L_{m}} V_{r e f},
$$

where $\left|Z_{L}\right|^{2}=\omega^{2} L_{L}^{2}+R_{L}^{2}$. Finally, replacing $v_{F}=v_{F}^{*}$ from (9) in (8), $i_{d}^{*}, i_{q}^{*}$ and $i_{F}^{*}$ can be obtained.

\section{Control Design}

In this Section the Sliding Mode Control technique is applied to an isolated wound rotor synchronous generator feeding an inductive load. The WRSG parameters are assumed to be constant. First, a switching function is designed, then, the equivalent control is computed and a switching controller is obtained. As mentioned before, a system dynamics extension is carried out in order to the switching surface has relative degree one. Finally, the Ideal Sliding Dynamics is analyzed.

\section{A. Switching function and equivalent control}

According to the control goals the switching function, $s(x)$, is defined as

$$
s(x)=V_{s}^{2}-V_{r e f}^{2}
$$

where $V_{r e f}$ is the stator voltage amplitude reference. Using (2), (5) and taking into account (3), the switching function can be given as a function of the state variables

$$
\begin{aligned}
s(x)= & \left(-R_{L} i_{d}+\omega L_{L} i_{q}-L_{L} \frac{\mathrm{d} i_{d}}{\mathrm{~d} t}\right)^{2} \\
& +\left(-R_{L} i_{q}-\omega L_{L} i_{d}-L_{L} \frac{\mathrm{d} i_{q}}{\mathrm{~d} t}\right)^{2}-V_{r e f}^{2}
\end{aligned}
$$

where $\frac{\mathrm{d} i_{d}}{\mathrm{~d} t}$ and $\frac{\mathrm{d} i_{q}}{\mathrm{~d} t}$ are respectively given in (6) and (7). 
Since $s(x)$ has relative degree zero, the system (4) is extended by considering $v_{F}$ as a new state variable and its derivative $\frac{\mathrm{d} \nu_{F}}{\mathrm{~d} t}$ as a fictitious input, i.e. a new input $u$ is defined by

$$
\frac{\mathrm{d} v_{F}}{\mathrm{~d} t}=k u,
$$

for a positive constant $k$. The extended system can be written as

$$
\mathcal{L} \frac{\mathrm{d} z}{\mathrm{~d} t}=\mathcal{A} z+\mathcal{B} u
$$

where $z^{T}=\left(i_{d}, i_{q}, i_{F}, v_{F}\right)$ and $u$ are, respectively, the new state and input variables,

$$
\begin{gathered}
\mathcal{A}=\left(\begin{array}{cccc}
-\left(R_{S}+R_{L}\right) & \omega\left(L_{s}+L_{L}\right) & 0 & 0 \\
-\omega\left(L_{s}+L_{L}\right) & -\left(R_{S}+R_{L}\right) & -\omega L_{m} & 0 \\
0 & 0 & -R_{F} & 1 \\
0 & 0 & 0 & 0
\end{array}\right), \\
\mathcal{L}=\left(\begin{array}{ll}
\hat{L} & 0 \\
0 & 1
\end{array}\right)
\end{gathered}
$$

and

$$
\mathcal{B}=\left(\begin{array}{l}
0 \\
0 \\
0 \\
k
\end{array}\right) .
$$

The equivalent control, $u_{e q}$, defined so that $\dot{s}=0$, results in

$$
u_{e q}=-\left(\frac{\partial s}{\partial z} \mathcal{L}^{-1} \mathcal{B}\right)^{-1} \frac{\partial s}{\partial z} \mathcal{L}^{-1} \mathcal{A} z
$$

taking into account that $\mathcal{B}$ has zeros in the first, second and third row, $\mathcal{L}^{-1}$ contains only a non-zero term in the fourth row and $v_{q}$ does not depend on $v_{F}$ and using some algebra yields,

$$
u_{e q}=-\frac{\mu_{d}}{2 k L_{L} L_{m}} \frac{1}{v_{d}}\left(\frac{\partial s}{\partial z} \mathcal{L}^{-1} \mathcal{A} z\right) .
$$

Note that sliding motion can only be expected in the subspace defined by $v_{d} \neq 0$. 


\section{B. Ideal Sliding Dynamics}

The Ideal Sliding Dynamics (ISD), i.e. the dynamics on the sliding surface (presumed an infinite switching frequency), is obtained assuming $\frac{\mathrm{d} s}{\mathrm{~d} t}=0$ together with $s(x)=0$. This implies $u=u_{e q}$ and

$$
v_{d}(x)=\sqrt{V_{r e f}^{2}-v_{q}^{2}(x)} .
$$

where $v_{q}(x)=D_{q} \cdot x$, with

$$
D_{q}=\left(0,-\frac{1}{\mu_{q}}\left(R_{L} L_{s}-R_{s} L_{L}\right), \quad \omega \frac{L_{m} L_{L}}{\mu_{q}}\right) .
$$

Using (11) with (6) and (7), the field voltage can be expressed as

$$
v_{F}(x)=c\left(v_{d}(x)-D_{d} \cdot x\right)
$$

where

$$
D_{d}=\left(-R_{L}+\frac{L_{F}}{c L_{m}}\left(R_{S}+R_{L}\right),-\omega \frac{L_{m}}{c},-\frac{R_{F}}{c}\right),
$$

and $c=\frac{\mu_{d}}{L_{L} L_{m}}>0$.

Replacing $u=u_{e q}$, and using (17) and (16) in (13), the ISD results in

$$
\hat{L} \dot{x}=A x+c B\left(v_{d}(x)-D_{d} x\right)
$$

that in terms of the error, $e=x-x^{*}$, with respect to any of the two equilibrium points can be written as

$$
\hat{L} \dot{e}=\left(A-c B D_{d}\right) e+c B \xi(e),
$$

where

$$
\xi(e)=v_{d}\left(e+x^{*}\right)-v_{d}^{*}
$$

and $v_{d}^{*}=v_{d}\left(x^{*}\right)$. Note that at the equilibria, $e=0, \xi(e)$ vanishes, and the linear part is stable if $L_{L}<\frac{L_{s} R_{L}}{R_{s}}$, see the Appendix.

Following the generalised Krasovski theorem, local stability (and the domain of attraction) can be proved using the positive definite function $V=f^{T} \hat{L} f$ as a Lyapunov candidate, where $f(e)=\dot{e}$, i.e.,

$$
f(e)=\hat{L}^{-1}\left(\left(A-c B D_{d}\right) e+c B \xi(e)\right)
$$


has been defined. Moreover note that

$$
\dot{f}=\hat{L}^{-1} M(e) f
$$

where $M(e)=A-c B\left(D_{d}-\frac{\partial \xi}{\partial e}\right)$, in fact

$$
M(e)=\left(\begin{array}{ccc}
-\left(R_{s}+R_{L}\right) & \omega\left(L_{s}+L_{L}\right) & 0 \\
-\omega\left(L_{s}+L_{L}\right) & -\left(R_{s}+R_{L}\right) & -\omega L_{m} \\
\alpha_{1} & \alpha_{2} \frac{v_{q}(e)}{v_{d}(e)}+\omega L_{m} & -\alpha_{3} \frac{v_{q}(e)}{v_{d}(e)}
\end{array}\right),
$$

with

$$
\begin{aligned}
& \alpha_{1}=c R_{L}-\frac{L_{F}}{L_{m}}\left(R_{s}+R_{L}\right), \\
& \alpha_{2}=\frac{R_{L} L_{s}-R_{s} L_{L}}{\mu_{q}}, \\
& \alpha_{3}=\frac{\omega L_{m} L_{L}}{\mu_{q}},
\end{aligned}
$$

and $v_{d}$ and $v_{q}$ previously defined by (16) and $v_{q}(e)=D_{q} \cdot e$.

The derivative of the Lyapunov function, using (III-B), yields

$$
\dot{V}=f^{T}\left(M+M^{T}\right) f
$$

and a necessary condition for $M+M^{T}<0$, is given by

$$
-4\left(R_{S}+R_{L}\right) \alpha_{3} \frac{v_{q}(e)}{v_{d}(e)}+\alpha_{1}^{2}+\alpha_{2}^{2}\left(\frac{v_{q}(e)}{v_{d}(e)}\right)^{2}<0 .
$$

Then, the stability of (18) is guaranteed if the previous inequality is fulfilled. Notice that (19) also implies $\frac{v_{q}}{v_{d}}>0$. Figure 2, plot the region where the inequality (19) fulfills. This numerical analysis corresponds to the experimental case presented in Section V (see the WRSG parameters in Table II) and shows that for a given load value, there exists two invariant regions (one of each containing one equilibrium point) where the trajectories go the equilibrium point. 


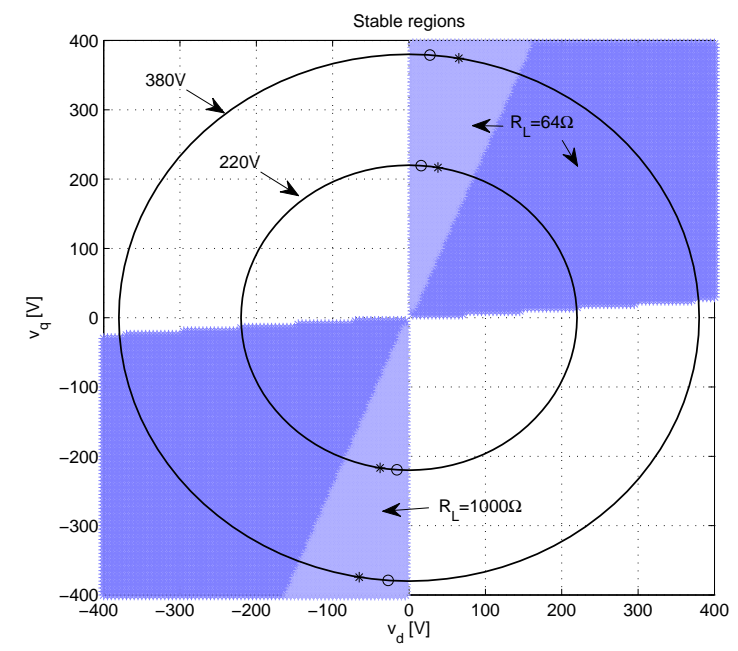

Figure 2. Stability regions depending on the dq-voltage values for the experimental case presented in Section V. The colored areas correspond to stable regions for $R_{L}=64 \Omega$ (both dark and light zones) and $R_{L}=1000 \Omega$ (only the light zone). The equilibrium points given by two stator voltage amplitude references, $220 \mathrm{~V}$ and $380 \mathrm{~V}$, are also depicted with an asterisk $\left(R_{L}=64 \Omega\right)$ and a circle $\left(R_{L}=1000 \Omega\right)$.

\section{Sliding Mode Controller}

Sliding mode controller is in charge of ensuring local attractiveness and flow invariance for the subset of the switching surface where sliding modes hold. Proceeding as usual, the switching action is designed so that $s \frac{\mathrm{d} s}{\mathrm{~d} t}<0$. Adding and subtracting $\mathcal{B} u_{\text {eq }}$, taking into account (14) and particularizing all of the computations to the model given in (13) and to the switching function (10) one yields

$$
s \frac{\mathrm{d} s}{\mathrm{~d} t}=-s v_{d}\left(u-u_{e q}\right)
$$

Hence,

$$
u=u_{e q}+\operatorname{sign}\left(s v_{d}\right),
$$

entails

$$
s \frac{\mathrm{d} s}{\mathrm{~d} t}=-\left|s v_{d}\right| \leq 0 .
$$

If the control input $u$ takes values in the discrete set $\left\{u_{1}, u_{2}\right\}$, where $u_{1}<u_{2}$ is presumed, the input $u$ 
is defined as

$$
u=\left\{\begin{array}{lll}
u_{1} & \text { if } & -s v_{d}>0 \\
u_{2} & \text { if } & -s v_{d}<0
\end{array}\right.
$$

which also assures (20) in the subset of the sliding surface where $u_{1} \leq u_{e q} \leq u_{2}$. Note that the (fictitious) input $u$ is a function that neither depends on the load values nor on the machine parameters. In turn, the switching function only depends on $v_{d}$ and $v_{q}$ (which are measured). Therefore, the closed loop system is robust to parameter variations and to load values. It is worth to mention the simplicity of (21) compared with the control law presented in [24].

A more complicated task is to analytically relate the range of $\left[u_{1}, u_{2}\right]$ to the sliding domain and its basin of attraction. This is non trivial because of the expression of $u_{e q}$, see equation (15). However, $u_{e q}$ evaluated in equilibrium points is zero. Indeed,from (15),

$$
u_{e q \mid x=x^{*}}=-\frac{\mu_{d}}{2 k L_{L} L_{m}} \frac{1}{v_{d}^{*}}\left(\frac{\partial s}{\partial z} \mathcal{L}^{-1} \mathcal{A} z^{*}\right),
$$

In addition, from $\mathcal{A}$ and $\mathcal{B}$ in (13), the equilibrium point $z^{*}$ must fulfill $\mathcal{A} z^{*}=0$. Consequently, $u_{1}<0<u_{2}$ ensures that there are sliding modes in a neighborhood of the ideal sliding dynamics equilibrium point. Better definitions for $u_{1}$ and $u_{2}$ require computing upper and lower bounds for the WRSG states in (22). The control law designed for the extended system, is applied to the actual plant using (12), i.e.,

$$
v_{F}=k \int u \mathrm{~d} t
$$

where $u$ is given in (21). It is worth noting that the control here reported is substantially different than the classic integral action ${ }^{2}$ (integral of the error instead of $u$ ). Also, the control gain $k$ and the values of $u_{1}$ and $u_{2}$ are redundant, which implies that for the final implementation one of them can be disregarded (for instance, setting $k=1$ ). Moreover, assuming $v_{d}>0$ and setting $\left|u_{1}\right|=\left|u_{2}\right|=\frac{\gamma}{k}$, the control law (21)

\footnotetext{
${ }^{2}$ For instance the one used in a proportional-integral (PI) controller, $v_{F}=k_{P} \tilde{V}_{s}+k_{I} \int \tilde{V}_{s} \mathrm{~d} t$, where $\tilde{V}_{s}=V_{r e f}-V_{s}$.
} 
with (23) results in

$$
\begin{aligned}
v_{F} & =-\gamma \psi \\
\dot{\psi} & =\operatorname{sign}(s) .
\end{aligned}
$$

Figure 3 shows the proposed control scheme. It needs the stator voltages and the rotor position as inputs and provides a continuous function $v_{F}$ as output. $v_{F}$ would be implemented by means of a pulse width modulator (PWM). The control algorithm does not require the knowledge of the WRSG and the load parameters. Only, it should be guaranteed the conditions given in Section III-B to ensure the stability of the ISD. Also, thanks to the dynamic extension, the discontinuous control action is filtered (by the integrator block before $v_{F}$ ) which helps to minimize the possible ripple of the state variables, also known as the chattering phenomena.

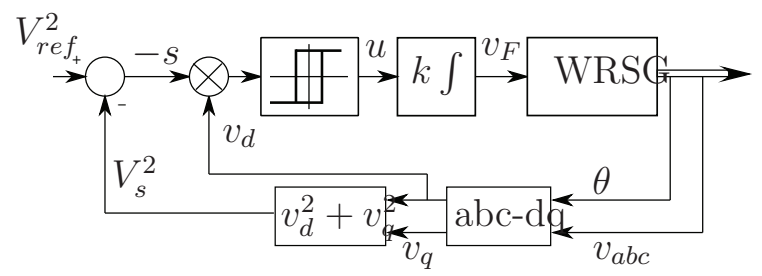

Figure 3. Control scheme.

\section{HARDWARE DESCRIPTION AND CONTROLLER IMPLEMENTATION}

\section{A. Hardware description}

Figure 4 shows the hardware scheme of the experimental setup. In this case, the WRSG is dragged by a DC motor (which acts as primary mover). Using two differential sensors the WRSG stator voltages are measured. The rotor position is obtained with a sensor coupled to the DC motor in order to compute the voltage $d q$-transformation. This transformation is required because the previously designed controller works in this reference frame. Notice that the mechanical speed measurement (or its reconstruction using the rotor position) is not necessary for the designed control algorithm. These measures are acquired by 


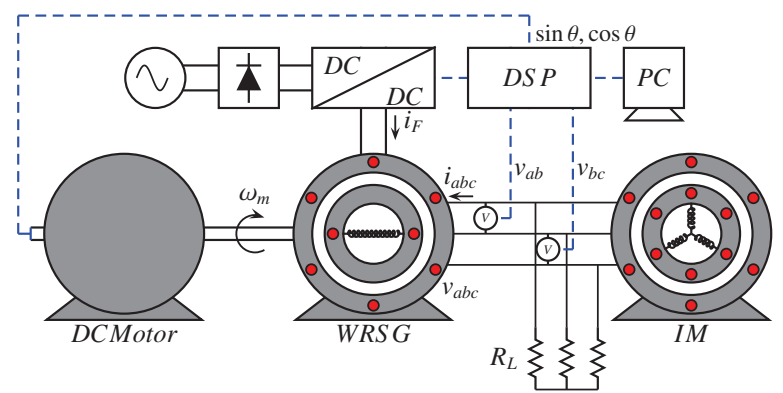

Figure 4. Interconnection scheme of the experimental setup.

the DSP which is programmed from a personal computer. The grid voltage is rectified in order to provide the DC bus voltage to the DC/DC power converter which applies the control defined by the DSP card to the WRSG. The DC motor used to provide a constant speed to the WRSG, is a $3 \mathrm{~kW}, 1500 \mathrm{rpm}$ machine, controlled by the 4Q2 commercial speed controller from Control Techniques Drives Ltd. For more detailed information see [29]. The WRSG is a $2.4 \mathrm{kVA}, 4$ poles three-phase machine. Its nameplate data are shown in Table I.

\begin{tabular}{ccc}
\hline$f=50 \mathrm{~Hz}$ & $n=1500 \mathrm{rpm}$ & $P=2.4 \mathrm{kVA}$ \\
\hline $3 \mathrm{ph}$ & $\Delta / \mathrm{Y}$ & $V_{F}=100 \mathrm{~V}$ \\
\hline$I_{F}=2.4 \mathrm{~A}$ & $V_{s}=220 / 380 \mathrm{~V}$ & $I_{s}=6.3 / 3.65 \mathrm{~A}$ \\
\hline
\end{tabular}

Table I

NAMEPLATE DATA OF THE WRSG.

The WRSG parameters, shown in Table II, ${ }^{3}$ were obtained using IEEE Std. 115-1995 [30].

\begin{tabular}{ccc}
\hline$R_{s}=3.06 \Omega$ & $L_{s}=0.48 \mathrm{H}$ & $R_{F}=39.65 \Omega$ \\
\hline$L_{m}=0.31 \mathrm{H}$ & $L_{F}=3.87 \mathrm{H}$ & $n=4$ \\
\hline$R_{F}^{\prime}=2.48 \Omega$ & $L_{F}^{\prime}=0.24 \mathrm{H}$ \\
\hline \multicolumn{3}{c}{ Table II }
\end{tabular}

WRSG PARAMETERS.

\footnotetext{
${ }^{3}$ The apostrophe signal indicates that parameters are referred from the rotor to the stator, and $n$ is the transformation relationship.
} 
The power converter, is a full bridge DC/DC converter, which can provide $\pm V_{D C} \mathrm{~V}$. This voltage is obtained from the power grid with a diode rectifier, an L filter and a capacitor DC bus. This converter applies the control law defined by the DSP card to the WRSG rotor. In the experimental tests the bus voltage is set to $V_{D C}=137.5 \mathrm{~V}$.

The load is composed of a resistive bank (equivalent to $R_{L}=128 \Omega$ ) and a $736 \mathrm{~W}$ squirrel cage induction machine as inductive load. This scenario, with an induction machine load instead of a constant $L_{L}$ value, is used to test the robustness of the proposed controller.

\section{B. Control implementation}

The control algorithm is programmed into a Texas Instruments floating point $150 \mathrm{Mhz}$ Digital Signal Processor (DSP TMS 320F28335). The DSP has 12-bit resolution 16 ADC channels with a maximum conversion speed of 12.5 MSPS, 6 PWM and 6 HRPWM outputs and 88 GPIO pins which can be used for communication purposes.

Real Time Workshop C code generation from Matlab/Simulink allows the code implementation to be simplified to the DSP without using a C code editor directly. Texas Target support package is used to configure the ADC, PWM, SPI, GPIO ports and interruptions. The control action, $v_{F}$, is implemented through a $10 \mathrm{kHz}$ switching frequency PWM.

\section{EXPERIMENTAL RESULTS}

In this Section, a set of experiments using the designed controller are presented. Furthermore, in order to compare the proposed approach with an existing industrial technique, the tests are also performed using a linear PI controller. In both cases, the mechanical speed reference for the DC motor is set at $1500 \mathrm{rpm}$ that corresponds to $f=50 \mathrm{~Hz}$ for the synchronous machine. Also, the proposed controller is tested under speed variations in order to check its robustness. 


\section{A. Sliding mode controller}

Control parameters of (21) and (23) have been tuned at $k=1, u_{1}=-10^{5}$ and $u_{2}=10^{5}$. In the first experiment, a step change in the reference of the stator voltage amplitude from $250 \mathrm{Vrms}$ to $380 \mathrm{Vrms}$ is applied while the WRSG feeds the induction machine. Figures 5 and 6 show the three-phase stator voltage, $v_{s}$, and the switching function, $s$, respectively. At the bottom, the picture at top was zoomed around $t=0.5$ s. As it can be seen, the stator voltage amplitude is perfectly regulated. A frequency analysis reveals that the stator voltages does not contain significant other frequencies than $50 \mathrm{~Hz}$, and the THD remains close to $1 \%$. The switching function oscillates around zero but, the consequent chattering phenomenon is not reflected in the experimental test due to the filter effect of the digital to analog converter. The switch driver signal equivalent to the field voltage, $v_{F}$, and the fictitious equivalent control action are displayed in Figure 7. The high frequency noise is due to the measurement from the DSP card. It is interesting to note that commutation (sliding mode) is lost for a short period when the reference voltage changes. However, it recovers fastly, and the equivalent control returns into the operation strip.
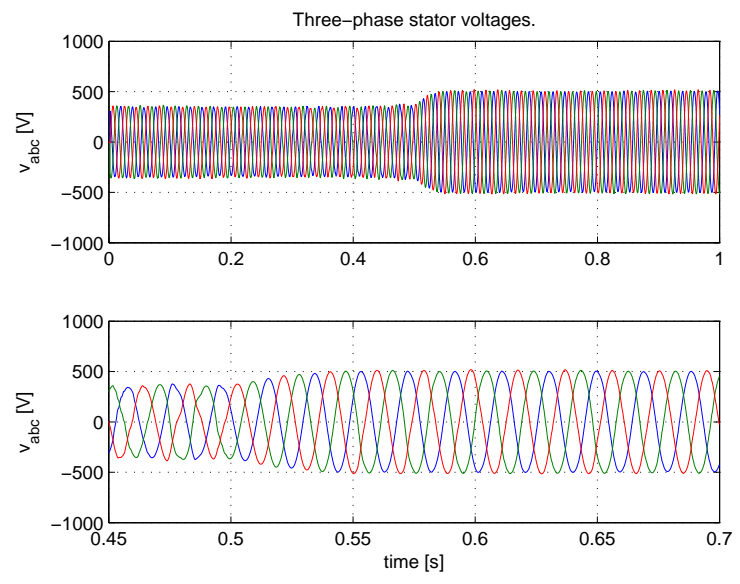

Figure 5. Three phase stator voltages, $v_{a b c}$ : Voltage reference change from $250 \mathrm{Vrms}$ to $380 \mathrm{Vrms}$ feeding an induction machine.

In the second and third experiments the controller is validated under load perturbations. The reference line voltage is set to 380 Vrms. First, the generator starts without any load and the induction machine is suddenly connected at $t=0.5 \mathrm{~s}$. Results are displayed in Figures 8, 9 and 10. The second perturbation 

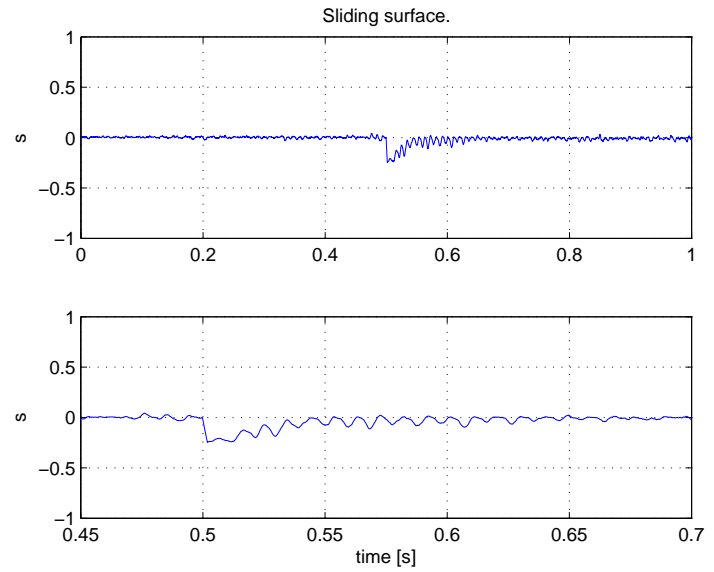

Figure 6. Switching function, $s(x)$ : Voltage reference change from $250 \mathrm{Vrms}$ to $380 \mathrm{Vrms}$ feeding an induction machine.
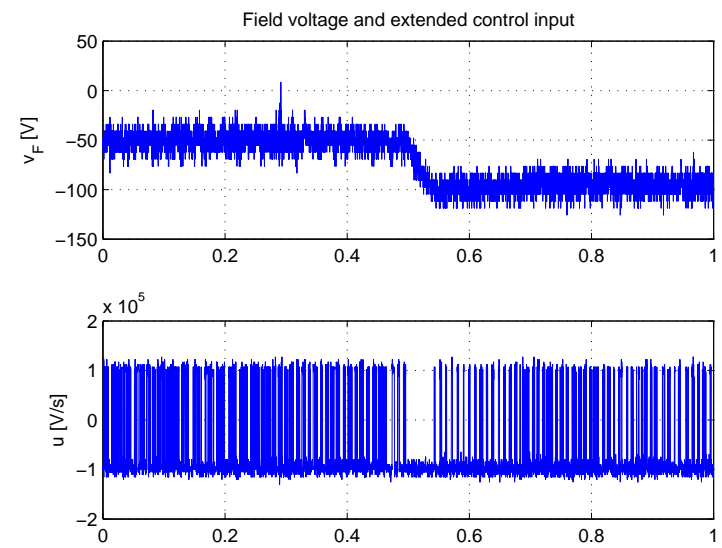

Figure 7. Field voltage action, $v_{F}$, and extended control input, $u$ : Voltage reference change from 250 Vrms to 380 Vrms feeding an induction machine.

consists in the generator feeding a resistive load (one half of the nominal load value) and then, at $t=0.5 \mathrm{~s}$, the induction machine is connected. See the obtained results in Figures 11, 12 and 13.

These two latter experiments show how the stator voltage regulation is achieved, recovering the reference value fastly after the load change. Furthermore, they also indicate that the time response is directly related to the $V_{D C}$ voltage, because during the transient time the control action remains saturated. 

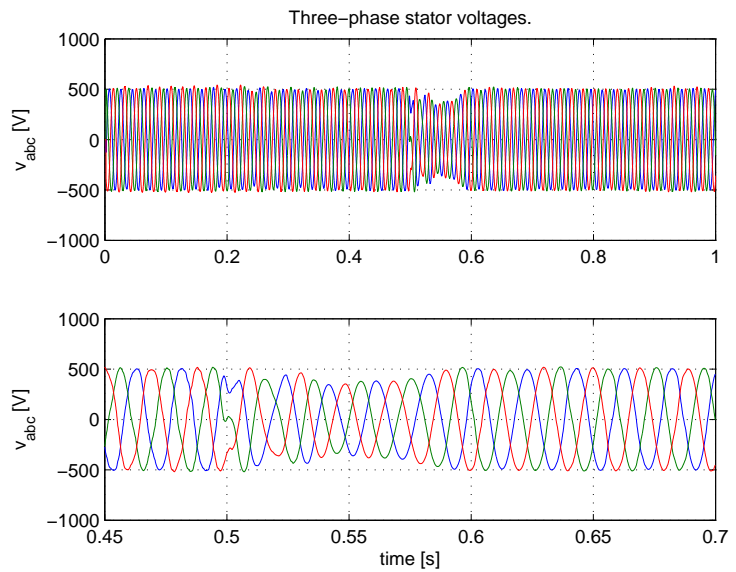

Figure 8. Three phase stator voltages, $v_{a b c}$ : Load change from no load to an induction machine connection.
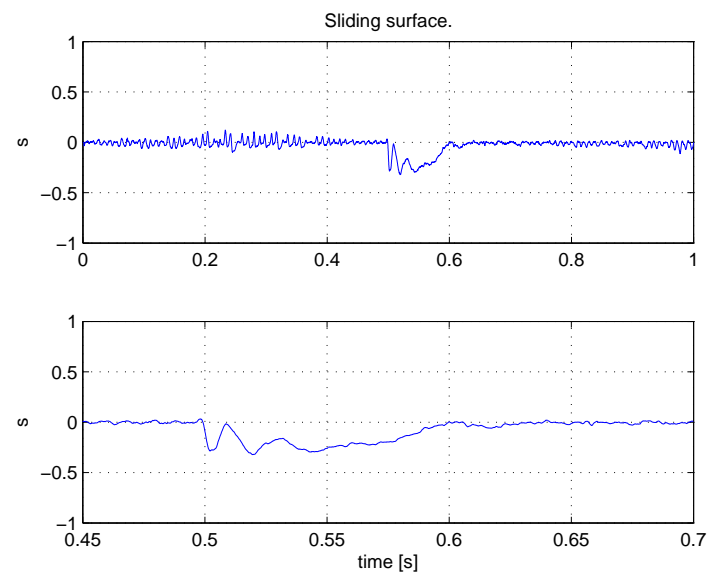

Figure 9. Switching function, $s(x)$ : Load change from no load to an induction machine connection.

\section{B. Comparison with a PI controller}

The experiments described in the previous subsection are also tested using a PI controller, i.e.,

$$
v_{F}=k_{P}\left(V_{r e f}-V_{s}\right)+k_{I} \int\left(V_{r e f}-V_{s}\right) \mathrm{d} t,
$$

where the gains have been set at $k_{P}=10$ and $k_{I}=0.1$.

Figure 14 compares the behavior of the stator voltages under a change of the reference, from $V_{r e f}=$ $250 \mathrm{Vrms}$ to $V_{r e f}=380 \mathrm{Vrms}$. Two subfigures (at the top and at the middle) display the three-phase stator voltages using the sliding mode controller and the PI design, respectively. The third figure (at the bottom) 

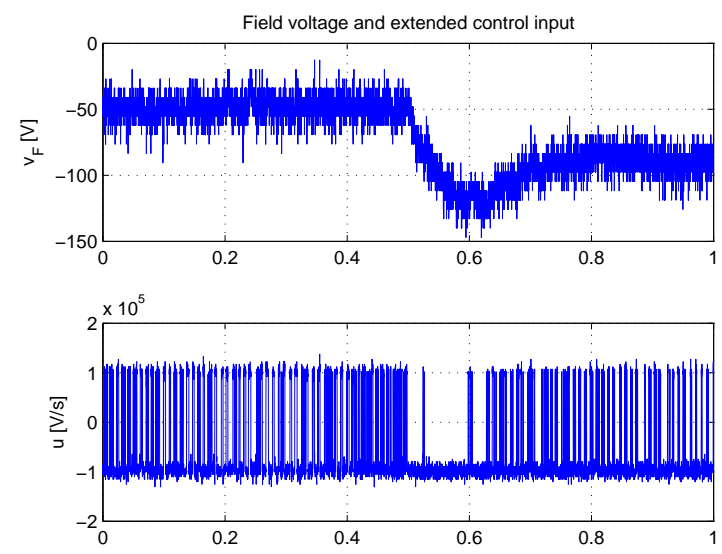

Figure 10. Field voltage action, $v_{F}$, and extended control input, $u$ : Load change from no load to an induction machine connection.
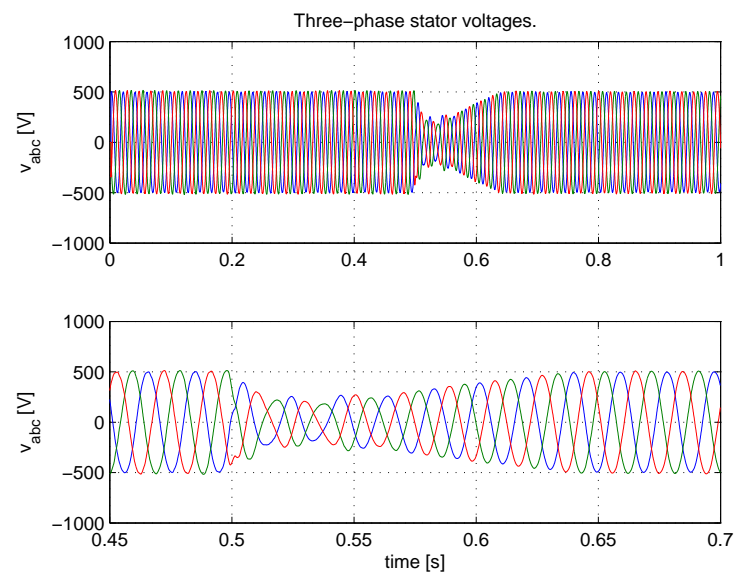

Figure 11. Three phase stator voltages, $v_{a b c}$ : Load change from half load to half load plus an induction machine connection.

represents the stator voltage amplitudes (scaled to the RMS value) for both cases. The load change test, starting without any load and then connecting the induction machine, is depicted in Figure 15.

The obtained results are similar using both techniques. The stabilizing time is practically the same (the PI controller is slightly faster when changing the reference, Figure 14). However, the sudden change of load implies a higher drop of voltage when using the PI controller (see Figure 15).

The advantage when implementing the sliding mode algorithm is its simplicity compared with the PI controller, which allow to reduce the computation time on the DSP around $15 \%(5.56 \mu$ s when using the sliding mode technique and $6.42 \mu \mathrm{s}$ for the PI controller). 

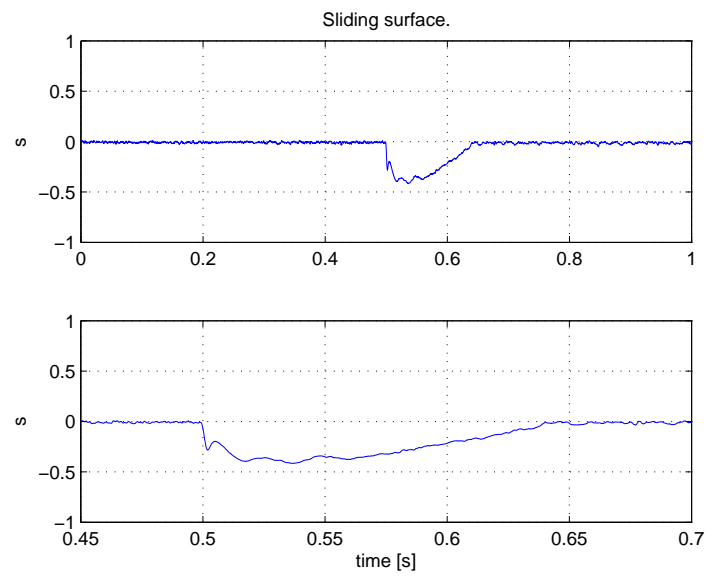

Figure 12. Switching function, $s(x)$ : Load change from half load to half load plus an induction machine connection.
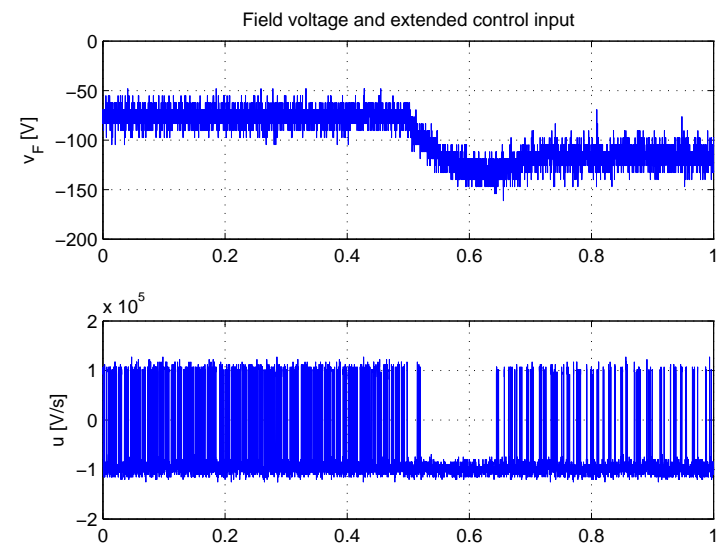

Figure 13. Field voltage action, $v_{F}$, and extended control input, $u$ : Load change from half load to half load plus an induction machine connection.

\section{Behavior under speed variations}

During the control design process a constant mechanical speed is assumed. However, in a practical scenario, the mechanical speed may be slightly variant with time. The proposed control algorithm is tested under a speed change (from 1500 to $1150 \mathrm{rpm}$ ). Figures 16 and 17 show the behavior of the $a$-phase stator voltage and the stator voltage amplitude, respectively. Note how the controller regulates the stator voltage independently on the rotor speed. Moreover, as it is expected, the speed variation only affects the stator voltage frequency, as appreciated in Figure 16. 

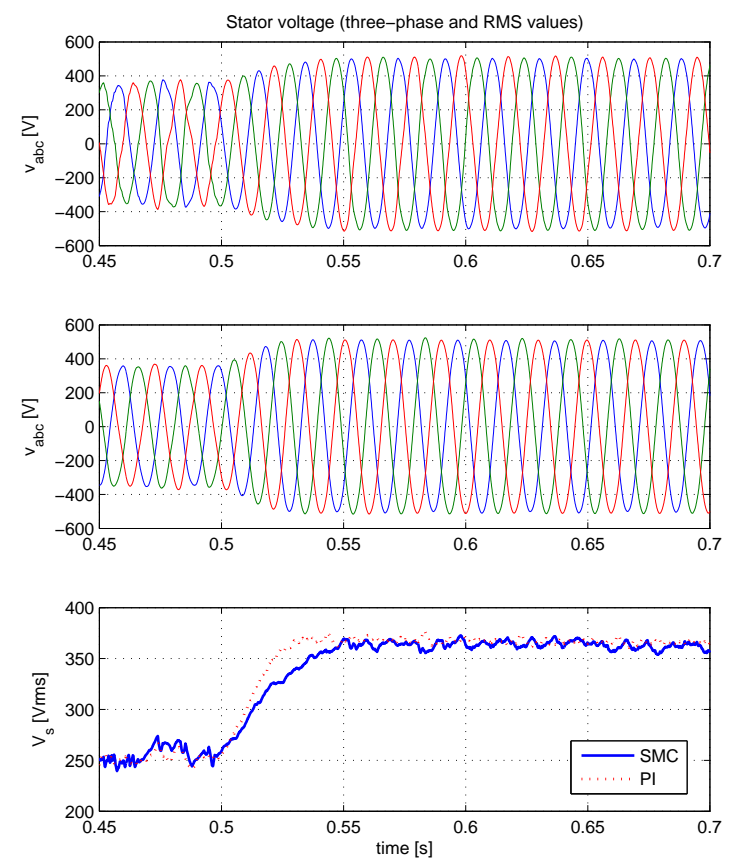

Figure 14. At the top and at the middle, Three-phase stator voltages, for SMC and PI controller, respectively, and their stator voltage amplitude (at the bottom): Voltage reference change from $250 \mathrm{Vrms}$ to $380 \mathrm{Vrms}$ feeding an induction machine.

\section{CONCLUSIONS}

A sliding mode controller for the stator voltage regulation of a WRSG feeding an isolated resistive-inductive load has been designed in this paper. The closed loop system regulates the stator voltage amplitude irrespectively of the load value, and it is robust in front of the WRSG parameters as well. Furthermore, the control implementation is very simple: it only measures the stator voltages and the rotor position (to compute the dq transformation). Moreover, the knowledge of the WRSG parameters is not required.

The control design involves a dynamic extension to overcome a zero relative degree output problem. This implies defining a fictitious control action which is integrated to obtain the actual field voltage to apply to the generator. The closed loop system has been analyzed and it results asymptotically stable.

The proposed controller is validated experimentally. Several tests, including step changes in the reference value and load perturbations, are performed. Results show a good regulation as well as robustness of the 

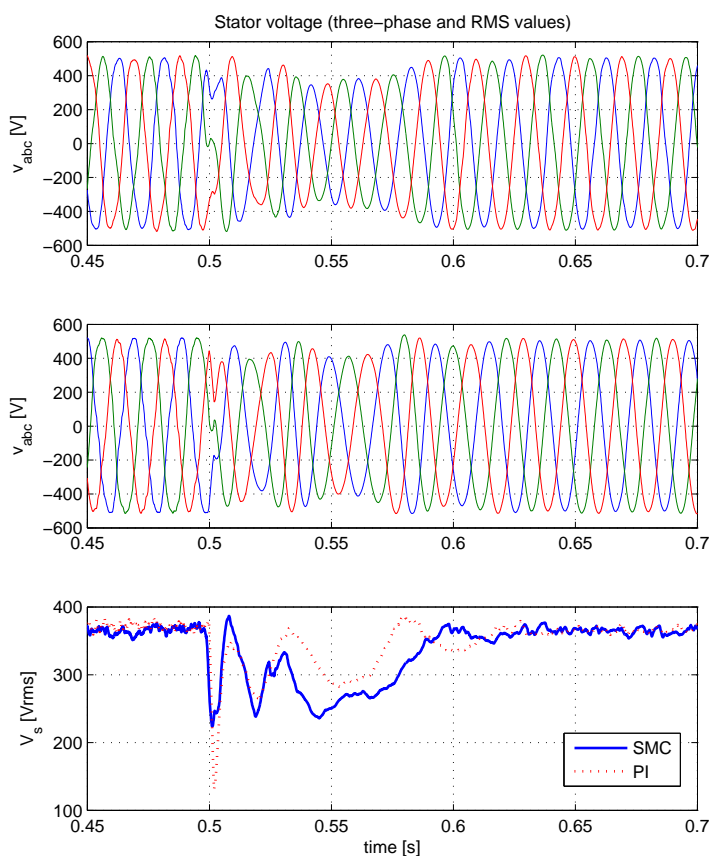

Figure 15. At the top and at the middle, Three-phase stator voltages, for SMC and PI controller, respectively, and their stator voltage amplitude (at the bottom): Load change from no load to an induction machine connection.
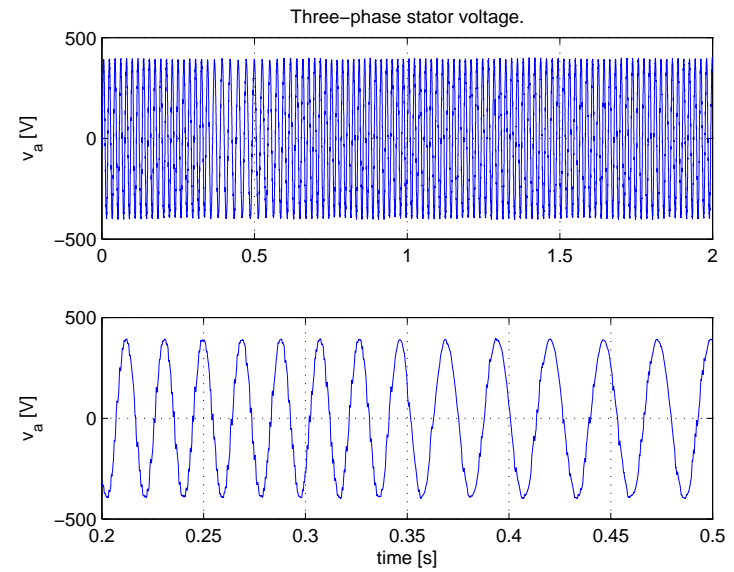

Figure 16. a-phase stator voltages: Speed change feeding an induction machine.

closed loop system. From the experimental tests, it can be observed that the proposed control method is also able to work under speed variations.

Compared with other existing methods, the obtained algorithm guarantees stability in a state space 

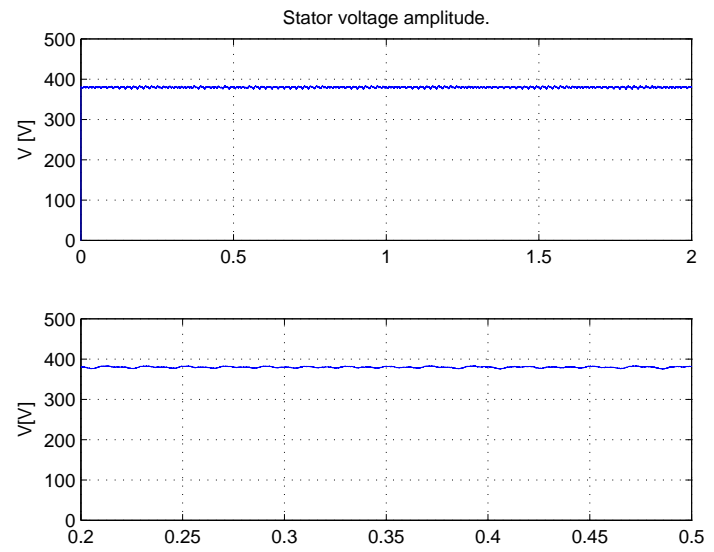

Figure 17. stator voltage amplitude: Speed change feeding an induction machine connection.

region, in front of the local stability provided by using the linear algorithms (as PI controllers). Experimentally, the proposed sliding mode controller offers a similar performance and accuracy than the PI controller, with the advantage that it reduces the computation time by $15 \%$. The main difference with respect the sliding mode controllers in [24][25][26] is the ability to regulate the stator voltage amplitude for inductive loads, moreover is considerably simpler and robust than the nonlinear control law proposed in [24].

\section{APPENDIX}

As mentioned in Section III, the stability of the linear part of the ISD is determined by the $\hat{L}^{-1}(A-$ $\left.c B D_{d}\right)$ matrix. Let us compute its characteristic polynomial

$$
\lambda_{3}+a_{2} \lambda_{2}+a_{1} \lambda_{1}+a_{0}
$$

where

$$
\begin{aligned}
& a_{2}=\frac{1}{\mu_{q} L_{L}}\left(L_{L}\left(R_{s}+R_{L}\right)+R_{L}\left(L_{s}+L_{L}\right)\right) \\
& a_{1}=\frac{1}{\mu_{q} L_{L}}\left(R_{L}\left(R_{s}+R_{L}\right)+\omega^{2} L_{L}\left(L_{s}+L_{L}\right)\right) \\
& a_{0}=\frac{1}{\mu_{q} L_{L}} \omega^{2}\left(R_{L} L_{S}-R_{S} L_{L}\right)
\end{aligned}
$$


From the Routh-Hurwitz criterion, sufficient conditions for stability are

$$
a_{2}, a_{0}>0
$$

together with

$$
a_{2} a_{1}-a_{0}>0
$$

From (24), $a_{2}>0$ is automatically fulfilled, and $a_{0}>0$ implies

$$
L_{L}<\frac{L_{S} R_{L}}{R_{S}}
$$

Replacing $a_{0}, a_{1}$ and $a_{2}$ in (25), this condition is also guaranteed for all parameter values. This implies that the system $\hat{L} \dot{e}=\left(A-c B D_{d}\right) e$ is stable if (26) is fulfilled.

\section{REFERENCES}

[1] P. Anderson, A. Fouad, Power System Control and Stability, The Iowa State University Press, 1977.

[2] P. Krause, F. Nozari, T. Skvarenina, D. Olive, The theory of neglecting stator transients, IEEE Trans. on Power Apparatus and Systems 98 (1) (1979) 141-148.

[3] N. Patin, L. Vido, E. Monmasson, J.-P. Louis, M. Gabsi, M. Lecrivain, Control of a hybrid excitation synchronous generator for aircraft applications, IEEE Trans. on Industrial Electronics 55 (10) (2008) 3772 -3783.

[4] E. Mouni, S. Tnani, G. Champenois, Synchronous generator output voltage real-time feedback control via $H_{\infty}$ strategy, IEEE Trans. on Energy Conversion 24 (2) (2009) 329-337.

[5] M. Seixas, R. Melcio, V. Mendes, Offshore wind turbine simulation: Multibody drive train. back-to-back $\{$ NPC $\}$ (neutral point clamped) converters. fractional-order control, Energy 69 (2014) 357 - 369.

[6] R. Muñoz-Aguilar, A. Dòria-Cerezo, P. Puleston, Energy-based modelling and simulation of a series hybrid electric vehicle propulsion system, in: Proc. European Conference on Power Electronics and Applications, 2009.

[7] R. Muñoz-Aguilar, A. Dòria-Cerezo, P. Puleston, Direct synchronous-asynchronous conversion system for hybrid electrical vehicle applications. an energy-based modeling approach, International Journal of Electrical Power \& Energy Systems 47 (2013) 264 -279.

[8] W. Leonhard, Control of electric drives, Springer, 1995.

[9] S. Chai, L. Wang, E. Rogers, Model predictive control of a permanent magnet synchronous motor with experimental validation, Control Engineering Practice 21 (11) (2013) 1584 - 1593, advanced Software Engineering in Industrial Automation (INCOM09). doi:http://dx.doi.org/10.1016/j.conengprac.2013.07.008.

URL http://www.sciencedirect.com/science/article/pii/S0967066113001445 
[10] Y. Ren, Z. Zhu, J. Liu, Direct torque control of permanent-magnet synchronous machine drives with a simple duty ratio regulator, Industrial Electronics, IEEE Transactions on 61 (10) (2014) 5249-5258. doi:10.1109/TIE.2014.2300070.

[11] A. Arias, C. Ortega, J. Zaragoza, J. Espina, J. Pou, Hybrid sensorless permanent magnet synchronous machine four quadrant drive based on direct matrix converter, International Journal of Electrical Power \& Energy Systems 45 (1) (2013) 78 - 86. doi:http://dx.doi.org/10.1016/j.ijepes.2012.08.073.

URL http://www.sciencedirect.com/science/article/pii/S0142061512005236

[12] M. Khanchoul, M. Hilairet, D. Normand-Cyrot, A passivity-based controller under low sampling for speed control of $\{$ PMSM $\}$, Control Engineering Practice 26 (2014) 20 - 27. doi:http://dx.doi.org/10.1016/j.conengprac.2013.12.013.

URL http://wWw.sciencedirect.com/science/article/pii/s0967066113002529

[13] W. Kemmetmller, D. Faustner, A. Kugi, Optimal torque control of permanent magnet synchronous machines using magnetic equivalent circuits, Mechatronics (2015) -doi:http://dx.doi.org/10.1016/j.mechatronics.2015.10.007.

URL http://www.sciencedirect.com/science/article/pii/S0957415815001683

[14] A. Stabile, J. O. Estima, C. Boccaletti, A. J. M. Cardoso, Converter power loss analysis in a fault-tolerant permanent-magnet synchronous motor drive, IEEE Transactions on Industrial Electronics 62 (3) (2015) 1984-1996.

[15] A. Magri, F. Giri, A. Abouloifa, M. Haloua, Nonlinear control of wound-rotor synchronous-motor, in: Proc. IEEE Int. Conf. Control Applications, 2006.

[16] J. B. X. Devotta, A dynamic model of the synchronous generator excitation control system, IEEE Trans. on Industrial Electronics 34 (4) (1987) 429-432.

[17] I. Jadrić, D. Borojević, M. Jadrić, Modeling and control of a synchronous generator with an active DC load, IEEE Trans. on Power Electronics 15 (2) (2000) 303-311.

[18] R. Schaefer, K. Kim, Excitation control of the synchronous generator, IEEE Industry Applications Magazine 7 (2) (2001) $37-43$.

[19] S. Funabiki, A. Hitsumoto, Y. Yamakawa, T. Ito, Automatic voltage regulation of synchronous generator with pole assignment self-tuning regulator, in: Proc. of the International Conference on of the Industrial Electronics, 1991.

[20] A. Barakat, S. Tnani, G. Champenois, E. Mouni, A new approach for synchronous generator terminal voltage control - comparison with a standard industrial controller, Electric Power Systems Research 81 (7) (2011) 1592-1601.

[21] K. Berkoune, E. B. Sedrine, L. Vido, S. L. Ballois, Robust control of hybrid excitation synchronous generator for wind applications, Mathematics and Computers in Simulation (2015) -doi:http://dx.doi.org/10.1016/j.matcom.2015.10.002.

URL http://www.sciencedirect.com/science/article/pii/S0378475415002165

[22] V. Utkin, J. Guldner, J. Shi, Sliding Mode Control in Electromechanical Systems, Taylor and Francis, 1999.

[23] D. Biel, E. Fossas, SMC application in power electronics, in: A. Sabanovic, L. Fridman, S. Spurgeon (Eds.), Variable Structure Systems: from Principles to Implementation, Vol. 66, IEE Control Series, London, 2004, pp. 265-284.

[24] E. Mouni, S. Tnani, G. Champenois, Improvement of synchronous generator's transient state by using voltage source and sliding mode 
control, in: Proc. IEEE International Symposium on Industrial Electronics, 2008.

[25] R. Muñoz-Aguilar, A. Dòria-Cerezo, E. Fossas, R. Cardoner, Sliding mode control of a stand-alone wound rotor synchronous generator, IEEE Trans. on Industrial Electronics 58 (10) (2011) 4888-4897.

[26] A. Dòria-Cerezo, R. Muñoz-Aguilar, V. Utkin, E. Fossas, Control of a stand-alone wound rotor synchronous generator: two sliding mode approaches via regulation of the d-voltage component, IEEE Trans. on Control Systems Technology 20 (3) (2012) 779-786.

[27] S. Heier, Grid Integration of Wind Energy Conversion Systems, 2nd Edition, John Wiley \& Sons Inc., 2006.

[28] P. Krause, O. Wasynczuk, S. Sudhoff, Analysis of Electric Machinery and Drive Systems, John Wiley \& Sons Inc., 2002.

[29] C. T. D. Ltd, 4Q2 User Guide: 0.55 - 7.5kW D.C.Motor Regenerative Speed Controller (2007).

[30] IEEE Guide: Test Procedures for Synchronous Machines. Std.115-1995, Tech. rep., IEEE (1995). 